\title{
Associating liver partition and portal vein ligation for staged hepatectomy
}

Clavien, Pierre A ; Lillemoe, Keith D

DOI: https://doi.org/10.1097/SLA.0000000000001534

Posted at the Zurich Open Repository and Archive, University of Zurich ZORA URL: https://doi.org/10.5167/uzh-119182

Journal Article

Published Version

Originally published at:

Clavien, Pierre A; Lillemoe, Keith D (2016). Associating liver partition and portal vein ligation for staged hepatectomy. Annals of Surgery, 263(5):835-836.

DOI: https://doi.org/10.1097/SLA.0000000000001534 


\title{
Associating Liver Partition and Portal Vein Ligation for Staged Hepatectomy
}

\author{
Pierre A. Clavien, MD, PhD, ${ }^{*}$ and Keith D. Lillemoe, MD $\dagger$
}

E ew surgical procedures have triggered so many reactions and emotions as the novel 2-stage - hepatectomy known as the "associating liver partition and portal vein ligation for staged hepatectomy" (ALPPS) procedure. ${ }^{1,2}$ Almost every liver surgeon has developed a strong personal opinion-positive or negative - about ALPPS. The rationale behind this particular attention, perhaps, relies on the introduction of a highly complex 2-step surgical procedure designed to cure an advanced and lethal disease (ie, multiple nonresectable liver tumors of various origins), associated with an enthusiastic editorial in the Journal suggesting that "this novel concept represents one of the most promising advances in oncological liver surgery so far." 2 On one hand, ALPPS triggers a rapid and spectacular liver regeneration of a small part of the liver after the first stage of the operation, which is in the range of what is observed after major hepatectomy, but on the other hand it is associated in several series with poor outcomes and high mortality rates after the second operation (completion hepatectomy).

Anticipating many controversies, an international registry was put in place shortly after the initial report of ALPPS in 2012,, ${ }^{3,4}$ which currently counts more than 650 entered cases. Using this registry and an analysis of more than 100 publications available on ALPPS, a 2-day expert meeting was convened in Hamburg, Germany in February 2015. Many aspects including technical features and indications, as well as short and long-term outcome measures were evaluated through presentations of panels of experts and discussion with the audience. Although this initial meeting was not a formal consensus conference with a jury, as recently reported for laparoscopic liver resections, ${ }^{5,6}$ it nevertheless enabled the identification of key issues. A summary of the main features of the meeting is presented below in the form of 8 recommendations. ${ }^{7}$

Considering the 5 developmental stages of a new surgical procedure (IDEAL - Idea Development - Exploration - Assessment - Long-term Study), as suggested by the Balliol group, ${ }^{8-10}$ ALPPS has reached the third stage, also called "Exploration Stage." This stage corresponds to the expansion of a technique creating innovative variants, which in ALPPS already led to a series of neologisms and acronyms. These terms are inconsistently used throughout the literature and in the international ALPPS registry, creating the risk of misunderstanding and confusion. Particularly in this developmental stage, it is essential to secure a common language to adequately compare and further develop different variants of the original technique. To address this shortcoming, the founding members and coordinator of the international ALPPS registry worked on a "consensus" terminology for ALPPS ${ }^{11}$ variants based on the current literature, the ALPPS registry, and a survey among all members of the registry.

\section{REFERENCES}

1. Schnitzbauer AA, Lang SA, Goessmann H, et al. Right portal vein ligation combined with in situ splitting induces rapid left lateral liver lobe hypertrophy enabling 2-staged extended right hepatic resection in small-for-size settings. Ann Surg. 2012;255:405-414.

2. de Santibanes E, Clavien PA. Playing Play-Doh to prevent postoperative liver failure: the "ALPPS" approach. Ann Surg. 2012;255:415-417.

3. Schadde E, Ardiles V, Robles-Campos R, et al. Early survival and safety of ALPPS: first report of the International ALPPS Registry. Ann Surg. 2014;260:829-836.

4. Schadde E, Raptis DA, Schnitzbauer AA, et al. Prediction of mortality after ALPPS stage-1: an analysis of 320 patients from the International ALPPS Registry. Ann Surg. 2015;262:780-786.

5. Wakabayashi G, Cherqui D, Geller DA, et al. Recommendations for laparoscopic liver resection: a report from the second international consensus conference held in Morioka. Ann Surg. 2015;261:619-629.

6. Clavien PA, Barkun J. Consensus conference on laparoscopic liver resection: a jury-based evaluation. Ann Surg. 2015;261:630-631.

7. Oldhafer KJ, Stavrou GA, Van Gulik TM. ALPPS - Where do we stand, where do we go? A report from the 1st International Expert Meeting in Hamburg 2015. Ann Surg 2016; in press.

8. McCulloch P, Altman DG, Campbell WB, et al. No surgical innovation without evaluation: the IDEAL recommendations. Lancet. 2009;374: 1105-1112.

\footnotetext{
From the *Department of Surgery and Transplantation, University Hospital Zurich, Zurich, Switzerland; and †Department of Surgery, Massachusetts General Hospital, Boston, MA.

Reprints: Pierre A. Clavien, MD, PhD, Department of Surgery and Transplantation, University Hospital Zurich, Zurich, Switzerland. E-mail: clavien@access.uzh.ch Copyright (C) 2015 Wolters Kluwer Health, Inc. All rights reserved.

ISSN: 0003-4932/14/26105-0821

DOI: $10.1097 /$ SLA.0000000000001534
} 
9. Barkun JS, Aronson JK, Feldman LS, et al. Evaluation and stages of surgical innovations: the IDEAL recommendations. Lancet. 2009;374:1089-1096.

10. Ergina PL, Cook JA, Blazeby JM, et al. Challenges in evaluating surgical innovation: the IDEAL recommendations. Lancet. 2009;374:1097-1104.
11. Linecker M, Kron P, Lang H, de Santibañes E, Clavien PA.Too many languages in the ALPPS - Preventing another tower of Babel? Ann Surg 2016 ; in press. 